\title{
Effect of Zirconia Substitution on Structural and Mechanical Properties of ZTA Composites
}

\author{
M. Moazzam Hossen ${ }^{1 *}$, F.-U.-Z. Chowdhury², M. A. Gafur ${ }^{3}$, A.K.M. Abdul \\ Hakim $^{4}$, M. Belal Hossen ${ }^{2}$ \\ ${ }^{I}$ Department of Computer Science \& Engineering, International Islamic University Chittagong, Chittagong, \\ Bangladesh. \\ ${ }^{2}$ Department of Physics, Chittagong University of Engineering and Technology, Chittagong, Bangladesh. \\ ${ }^{3} P P$ and PDC, BCSIR, Dhaka, Bangladesh. \\ ${ }^{4}$ Department of Materials and Metallurgical Engineering, Bangladesh University of Engineering and \\ Technology, Dhaka, Bangladesh.
}

\begin{abstract}
Zirconia Toughened Alumina (ZTA) composites are attractive structural materials, which combine the high hardness and elastics modulus of the alumina matrix with additional toughening effects, due to the zirconia dispersion. In the present study, ZTA composites containing different amounts of zirconia (in the range $0-16 w t \%)$ were prepared by slurry method and sintered at $1450^{\circ} \mathrm{C}$ and $1550^{\circ} \mathrm{C}$ for two hour. Microstructure of the composites was observed using scanning electron microscopy and phase content was detected by means of $X$ - ray diffraction. Mechanical properties such as hardness, elastic modulus and flexural strength were measured. Density was increased with the increase of zirconia content for both sintering temperature, while grain size and elastic modulus was decreased with the same change of zirconia content. Hardness and flexural strength were carried out using the Vickers indentation and were discussed as a function of the $\mathrm{ZrO}_{2}$ content and sintering temperature. The toughening effect is attributed mainly to the zirconia $t \rightarrow m$ phase transformation. About $61 \%$ more flexural strength was found for $16 \mathrm{wt} \%$ ZTA composites when compared to the pure alumina.
\end{abstract}

Key words: Alumina-Zirconia composite, XRD, SEM, Hardness, Flexural strength.

\section{Introduction}

Alumina is one of the most widely used ceramic materials that have been successfully used in structural applications due to several desirable properties, e.g. high elastic modulus, high wear resistance, chemical corrosion resistance, high temperature stability and the retention of strength at high temperature. However, the drawback of common alumina is its poor mechanical properties, such as flexure strength and fracture toughness. There are many ways to overcome such weakness by making it as composite materials. It is well known that the mechanical properties of alumina ceramics can be considerably increased by the incorporation of fine zirconia particles [1-4]. Zirconia particles are frequently employed as a toughening agent for other ceramics, and these zirconia toughened ceramics have received great attention in the last two decades [5-7].

Therefore, alumina-Zirconia composites is an important class of toughened structural ceramics in which the strength and toughness have been improved due to stress induced tetragonal to monoclinic martensitic transformation toughening and microcrack toughening [8-10]. The extent of toughening achieved in this composites depend on the particle size of $\mathrm{Al}_{2} \mathrm{O}_{3}$ and $\mathrm{ZrO}_{2}$, volume fraction of $\mathrm{ZrO}_{2}$ retained in the metastable tetragonal phase as well as on the relative distribution of $\mathrm{Al}_{2} \mathrm{O}_{3}$ and $\mathrm{ZrO}_{2}$ in the matrix [11]. Finer particle sizes of both $\mathrm{Al}_{2} \mathrm{O}_{3}$ and $\mathrm{ZrO}_{2}$ will not only enhance the chances of a uniform $\mathrm{Al}_{2} \mathrm{O}_{3}$ and $\mathrm{ZrO}_{2}$ distribution, it also increases the possibility of $\mathrm{ZrO}_{2}$ being retained as metastable tetragonal phase [12]. It is reported that the incorporation of zirconia particles into alumina matrix significantly enhanced the mechanical properties compare to pure alumina.

The present work deals with the structural and mechanical properties of $\mathrm{Al}_{2} \mathrm{O}_{3}-\mathrm{ZrO}_{2}$ composites by slurry method. Preparation of various Zirconia Toughened Alumina compositions was done. X-ray Diffraction (XRD) patterns and microstructures were analyzed. Physical properties such as density and porosity and mechanical properties such as microhardness, elastic modulus and flexural strength were determined.

\subsection{Sample Preparation}

\section{Experimental}

The commercially available powders used in this work were the nanocrystalline, $\alpha-\mathrm{Al}_{2} \mathrm{O}_{3}$ powder and yttria-stabilized $\mathrm{ZrO}_{2}(3 \mathrm{~mol} \%)$ powder from the manufacturing company Inframat ${ }^{\circledR}$ Advanced Materials ${ }^{\mathrm{TM}}$, USA. Alumina presented crystal size $\sim 40 \mathrm{~nm}$ and particle size $\sim 150 \mathrm{~nm}$ and zirconia presented average particle 
size 30-60 nm. To prepare different composition, related powders were weighed by following unitary method, keeping the total weight constant.

Different compositions had been prepared by varying $\mathrm{ZrO}_{2}$ content from 4 to $16 \mathrm{wt} \%$ in the step of 4 wt \%. A pure $\mathrm{Al}_{2} \mathrm{O}_{3}$ sample was also prepared to compare its properties with those of ZTA composites. To attain the compositions, mechanical milling was performed in distilled water with $65 \mathrm{wt} \%$ of solid content for 24 hours in ball milling, with zirconia ball as a grinding media. Ammonium polyacrylate was used as dispersant. The slurry of the power mixtures was dried in an oven for 24 hours at $100^{\circ} \mathrm{C}$ and the dried lumps were crushed and passed through a plastic sieve. Hand milling was done for several hours to obtain a homogeneous distribution. Powder compacts with dimension of $5 \times 6 \times 50 \mathrm{~mm}$ were confirmed by uniaxiallly pressing at 60 $\mathrm{MPa}$. Before slurry, polyvinyl alcohol (PVA) was mixed as a binder with the powder to provide some green strength for subsequent handling. The withdrawal of the binder was carried through in a muffle furnace with heating rate $6{ }^{\circ} \mathrm{C} / \mathrm{min}$ at $600{ }^{\circ} \mathrm{C}$ per $180 \mathrm{~min}$. The sintering was carried out in a box furnace at $1450^{\circ} \mathrm{C}$ and $1550^{\circ} \mathrm{C}$ for two hours with a heating rate of $20^{\circ} \mathrm{C} / \mathrm{min}$. The bulk densities of the sintered samples were measured from the ratio weight/volume. The sintered specimens were machined longitudinally with a 325 gritresin bonded diamond wheel at a depth of $5 \mu \mathrm{m} /$ pass. The final dimensions of the specimens were $3 \times 4 \times 35 \mathrm{~mm}$.

\subsection{Measurements}

Phase identification was confirmed by powder X-ray diffractometry (XRD) technique using BRUKER X-Ray Diffractometer of Model D8 Advance with $\mathrm{Cu}-K_{\alpha}$ radiation $(\lambda=1.54 \AA$ ). For each sample a scan has been performed from $20^{\circ}$ to $75^{\circ}$ with a step size of $0.02^{\circ}$. The volume fraction of monoclinic zirconia $\left(\mathrm{V}_{\mathrm{m}}\right)$ was calculated according to the following equation:

$$
V_{m}=\frac{I_{(\overline{1} 11)_{m}}+I_{(111)_{m}}}{I_{(\overline{111})_{m}}+I_{(111)_{m}}+I_{(111)_{t}}}
$$

Theoretical density $\rho_{o}$ of the sample was calculated from the actual density of the starting powders and their weight percentages using the rule of mixtures [13]:

$\rho_{o}=\rho_{A} V_{A}+\rho_{Z} V_{Z}$

where $\rho_{A}, \rho_{Z}$ are the density and $V_{A}, V_{Z}$ are the volume fraction of $\mathrm{Al}_{2} \mathrm{O}_{3}$ and $\mathrm{ZrO}_{2}$ respectively. Values of $\rho_{A}=$ $3.97 \mathrm{gm} / \mathrm{cm}^{3}$ and $\rho_{\mathrm{Z}}=6.10 \mathrm{gm} / \mathrm{cm}^{3}$ have been used here to calculate $\rho_{o}$. The measured bulk density $\rho_{b}$ was determined using the formula:

$$
\rho_{b}=\frac{m}{\pi r^{2} h}
$$

Where $m$ is the mass, $r$ the radius and $h$ the height of the sample.

The porosity $\mathrm{P}$ of the sample was determined using the relation.

$$
P=\left(1-\frac{\rho_{b}}{\rho_{0}}\right) \times 100 \%
$$

Microstructures for the samples of different compositions were examined by using Philips XL-30 scanning electron microscopy (SEM). Mean linear intercept length $\bar{l}$ is used to determine the ASTM grain size number, $\mathrm{G}$, by using the linear intercept method:

$$
G=-3.2877+6.6439 \log _{10} \bar{l}
$$

where $\bar{l}$ is in millimeters at $1 \times$ Magnification.

The methodology used for the determination of hardness, was in accordance with ASTM C1327-99 [10]. Five Vickers impressions had been carried through in the surfaces of each one of the samples, which already have polished, using an applied load of $2 \mathrm{kgf}(19.6141 \mathrm{~N})$ during six seconds. After the diagonal length measurement, the values of the Vickers hardness (GPa) were calculated, by the following equation $[14,15]$ :

$$
H_{v}=0.01819 \times \frac{F}{d^{2}}
$$

Where $\mathrm{F}$ is the load in $\mathrm{N}$ and $\mathrm{d}$ is the average length of the two diagonals of the indentations in $\mathrm{mm}$. [16]:

The porosity dependence Elastic Modulus can also be measured using the Dewey-Mackenzie relation

$$
E=E_{o}(1-2 P)
$$


where $E$ is the effective elastic modulus of the porous composites, $E_{o}$ is the elastic modulus of the dense composites and $P$ is the porosity of the sample.

The flexural strength of the specimens was determined according with ASTM D790 - 10 by three-point bending method (Hounsfield Model H10KS-universal test machine), with a span of $30 \mathrm{~mm}$ and crosshead speed of $0.5 \mathrm{~mm} / \mathrm{min}$ at ambient room temperature conditions. The flexural strength was calculated from the following equation.

$$
\sigma_{\text {flexural }}=\frac{3 W L}{2 B D^{2}}
$$

where $W$ is the load $(\mathrm{N}), B$ is the width $(\mathrm{mm})$ and $D$ is the thickness $(\mathrm{mm})$ of the sample.

\section{Result And Discussion}

XRD analysis

The XRD patterns of a ZTA sample containing $0,4,8,12$ and $16 \mathrm{wt} \% \mathrm{ZrO}_{2}$ sintered at $1450^{\circ} \mathrm{C}$ and $1550^{\circ} \mathrm{C}$ are shown in Fig. 1. and Fig. 2. respectively which confirms the formation of multi-phase ZTA.

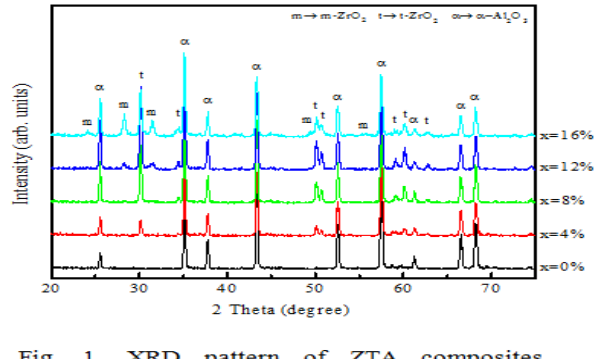

Fig. 1. XRD pattern of ZTA composites containing different wt $\% \mathrm{ZrO}_{2}$ and sintered at $1450^{\circ} \mathrm{C}$ for 2 hours.

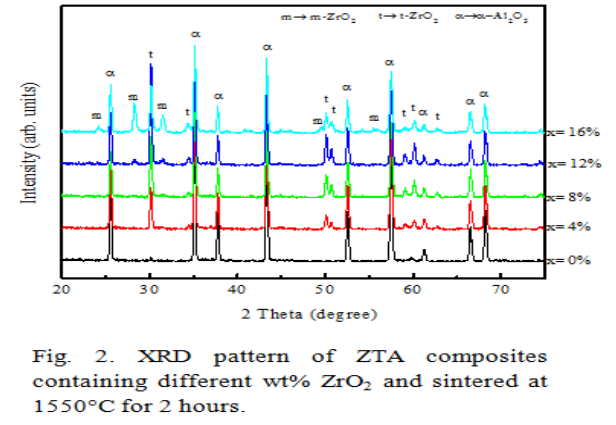

$1550^{\circ} \mathrm{C}$.

$\mathrm{XRD}$ analysis of the samples indicate that only $\alpha-\mathrm{Al}_{2} \mathrm{O}_{3}, \mathrm{t}$ and $\mathrm{m}-\mathrm{ZrO}_{2}$ are the crystalline phases present in the pure $\mathrm{Al}_{2} \mathrm{O}_{3}$ and in the ZTA composites, respectively. It is observed that at $4 \mathrm{wt} \%$ and $8 \mathrm{wt} \% \mathrm{ZrO}_{2}$ content, there is no $\mathrm{m}-\mathrm{ZrO}_{2}$ phase and all are $\mathrm{t}-\mathrm{ZrO}_{2}$ phase, while with the increase of $\mathrm{ZrO}_{2}$ content, $\mathrm{m}-\mathrm{ZrO}$, phase increases and the $\mathrm{t}-\mathrm{ZrO}_{2}$ phase decreases. However, $\mathrm{t}-\mathrm{ZrO}_{2}$ retention becomes much easier to trigger the transformation to monoclinic. As a result, its contribution to transformation toughening predominates. The extent of toughening achieved in the composites depend on the particle size of $\mathrm{Al}_{2} \mathrm{O}_{3}$ and $\mathrm{ZrO}_{2}$, volume fraction of $\mathrm{ZrO}_{2}$ retained in the metastable tetragonal phase as well as on the relative distribution of $\mathrm{Al}_{2} \mathrm{O}_{3}$ and $\mathrm{ZrO}_{2}$ in the matrix [17]. With the increase of $\mathrm{ZrO}_{2}$ content, intensity of some $\mathrm{t}-\mathrm{ZrO}_{2}$ peaks are reduced, whereas some $\mathrm{m}-\mathrm{ZrO}_{2}$ peaks are appeared and further intensity increases. So it can be inferred that monoclinic phase is indeed retained at the room temperature due to the presence of the hard alumina matrix and this phase is responsible for flexural strength improvement by transformation toughening mechanism. The effect of sintering temperature $1450^{\circ} \mathrm{C}$ and $1550^{\circ} \mathrm{C}$ on the XRD pattern of a ZTA composite containing $0,4,8,12$ and $16 \mathrm{wt} \% \mathrm{ZrO}_{2}$ has been shown in the related figure. From Fig. 1. and Fig. 2., it is observed that with the increase of sintering temperature more peaks for $\mathrm{ZrO}_{2}$ have been found. It also reveals that with the increase of sintering temperature, more $\mathrm{m}-\mathrm{ZrO}_{2}$ phases appear and the intensity of $\mathrm{t}-\mathrm{ZrO}_{2}$ decreases.

Fig. 3. shows the result of density as a function of zirconia content. Presence of $\mathrm{ZrO}_{2}$ results in a continuous increase in density. The theoretical density of $\mathrm{ZrO}_{2}$ is around $6.10 \mathrm{gm} / \mathrm{cc}$ whereas that of $\mathrm{Al}_{2} \mathrm{O}_{3}$ is $3.97 \mathrm{gm} / \mathrm{cc}$, therefore the effective density values of the alumina-zirconia rise with increasing $\mathrm{ZrO}_{2}$ content and a compact structure is formed. Sintering in practice is the control of both densification and grain growth. With the continual supply of thermal energy, more and more contact points are created between the particles and the intervening porosity diffuses out of the contact area. Hence a substantial increase in density is resulted. In the mean time the existing grains inside the particle have an opportunity to grow in order to minimize the overall energy of the system and some irregular grow of $\mathrm{t}-\mathrm{ZrO}_{2}$ leads the grain to transform to monoclinic.

Thus densification and grain growth occurs simultaneously. It shows that density increases with sintering temperature. We know that matter transport during the sintering of polycrystalline composites occurs by diffusion, a thermally activated process, which can occur along different paths in the solid, giving rise to the different mechanisms of diffusion: lattice, grain boundary and surface diffusion. The density result reveals that the elimination of pore, simultaneous grain growth with grain boundary diffusion and lattice diffusion are the predominant mechanism to compact the material at high temperature. In this work, the theoretical density calculated from the rule of mixture was found around $89.03 \%$ for pure $\mathrm{Al}_{2} \mathrm{O}_{3}$ and that of $93.04 \%$ for $16 \mathrm{wt} \%$ of ZTA sintered at $1450^{\circ} \mathrm{C}$ for 2 hours. In addition, about $96.57 \%$ of theoretical density was observed for pure $\mathrm{Al}_{2} \mathrm{O}_{3}$ and $97.89 \%$ that for same ZTA sintered at $1550^{\circ} \mathrm{C}$ for 2 hours. About $4-7 \%$ density has been changed due to increase of $100^{\circ} \mathrm{C}$ for both pure $\mathrm{Al}_{2} \mathrm{O}_{3}$ and $\mathrm{ZTA}$. This resembles that after increasing sintering temperature 
particles become more compact and dense. Moreover, increasing temperature and zirconia content, density increases more linearly than that of lower temperature and content.

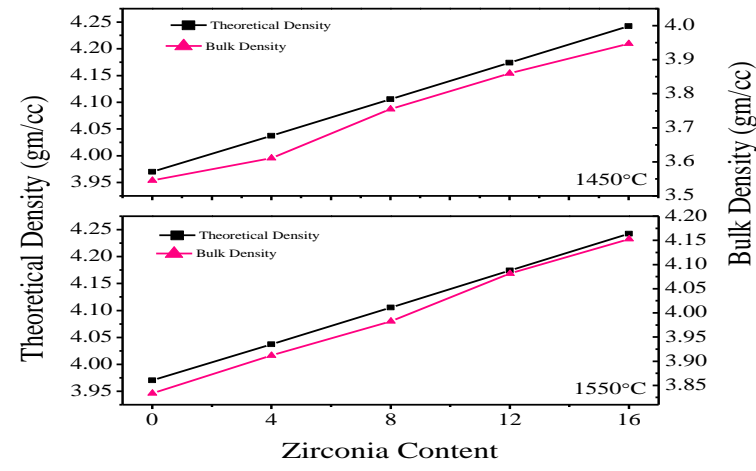

Fig. 3. Theoretical and Bulk Density as a function of zirconia content sintered at different temperatures for 2 hours.

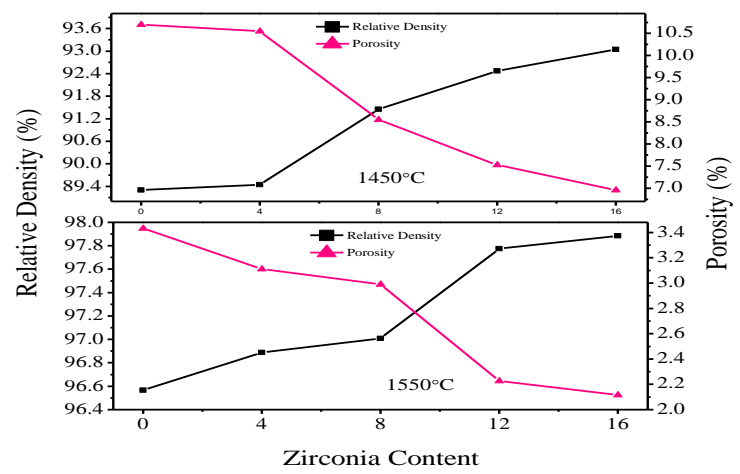

Fig. 4. Relative Density and Porosity as a function of zirconia content sintered at different temperatures for 2 hours.

Fig. 4. shows the effect of $\mathrm{ZrO}_{2}$ content and sintering temperature on the porosity of ZTA composites, respectively. It is observed that the porosity is decreased with $\mathrm{ZrO}_{2}$ content as well as sintering temperature. It resembles that the composites are in more compact form at the higher temperatures. During the diffusion process of sintering, the intervening porosity diffuses out, resulting in reduction of porosity. With the increase of temperature, sample becomes more homogeneous. During $100^{\circ} \mathrm{C}$ interval, porosity decreases sharply from low temperature to high temperature. It is also seen that the percentage of porosity is minimum at the sintering temperature $1550^{\circ} \mathrm{C}$ for all the composites than that of at $1450^{\circ} \mathrm{C}$, i.e., it reveals that the sample is more compact at $1550^{\circ} \mathrm{C}$.

\subsection{Scanning electron microscopy}

Fig. 5. (a)-(e) show the SEM micrographs of the ZTA composites containing different $\mathrm{wt}^{2} \mathrm{ZrO}_{2}$ at $1550^{\circ} \mathrm{C}$. When $\mathrm{ZrO}_{2}$ was added, the grains become finer compared to that of pure $\mathrm{Al}_{2} \mathrm{O}_{3}$, as shown in Fig. 5. (b)(e). Observations show highly homogeneous microstructures with some agglomerates, pores or abnormally grown alumina grains. The micrograph exhibits the $\mathrm{Al}_{2} \mathrm{O}_{3}$ and $\mathrm{ZrO}_{2}$ grains as dark and whitish color respectively, where zirconia grains are embedded around the alumina grain and within the grain.

From the figure, it can also be observed that $\mathrm{ZrO}_{2}$ particles are uniformly dispersed throughout the alumina matrix. As the amount of $\mathrm{ZrO}_{2}$ content increases, the $\mathrm{Al}_{2} \mathrm{O}_{3}$ grain size decreases significantly. The $\mathrm{ZrO}_{2}$ phase creates a pinning effect around $\mathrm{Al}_{2} \mathrm{O}_{3}$ grain and obstructs its growth. When $\mathrm{ZrO}_{2}$ is added with $\mathrm{Al}_{2} \mathrm{O}_{3}$, evenly distributed fine $\mathrm{ZrO}_{2}$ grains act as grain refiner and led to smaller $\mathrm{Al}_{2} \mathrm{O}_{3}$ grains. This is possibly due to increase in density as well as enhancement of mechanical properties. A fine grain size and refined microstructure are necessary for improved mechanical properties especially for wear resistance of dental implant.

From Fig. 6., it is observed that grain size of $\mathrm{Al}_{2} \mathrm{O}_{3}$ and $\mathrm{ZrO}_{2}$ vary with the amount of Zirconia content added with the pure $\mathrm{Al}_{2} \mathrm{O}_{3}$. In the present work, it is seen that when $\mathrm{ZrO}_{2}$ was added to $\mathrm{Al}_{2} \mathrm{O}_{3}$ then the grain size decreases appreciably. In this work, the grain size calculated from the linear intercept method have been found around $1.71 \mu \mathrm{m}$ for pure $\mathrm{Al}_{2} \mathrm{O}_{3}$ and that of $1.05 \mu \mathrm{m}$ for $16 \mathrm{wt} \%$ of ZTA sintered at $1450^{\circ} \mathrm{C}$ for 2 hours. In addition, grain size about $1.81 \mu \mathrm{m}$ has been observed for pure $\mathrm{Al}_{2} \mathrm{O}_{3}$ and $1.08 \mu \mathrm{m}$ that for same ZTA sintered at $1550^{\circ} \mathrm{C}$ for 2 hours.

\subsection{Hardness and elastic modulus}

The Vickers hardness of $\mathrm{Al}_{2} \mathrm{O}_{3}-\mathrm{ZrO}_{2}$ composites as a function of zirconia content at temperature $1450^{\circ} \mathrm{C}$ and $1550^{\circ} \mathrm{C}$, respectively are shown in Fig. 7. It has been observed that the hardness decreases with the increase of $\mathrm{ZrO}_{2}$ content. Zirconia has lower hardness than alumina and it can also obstruct the densification of the alumina phase. Again, amount of zirconia has an adverse affect on the hardness of the composites due to coarsening of the zirconia grains and formation of subsequent porosity. From the figure it is also clear that, for any particular composition, hardness increases with sintering temperature. As higher sintering temperature offers better densification, hardness value increases as a whole. Similar trend in hardness has been observed by R. P. Rana [18] and Basu et al. [19]. The hardness increases with sintering temperature for all compositions. At $1450^{\circ} \mathrm{C}$, maximum hardness shows $13.71 \mathrm{GPa}$ and at $1550^{\circ} \mathrm{C}$, it is $17.91 \mathrm{GPa}$, which is observed for pure Alumina. However, at same temperatures, minimum hardness shows $10.49 \mathrm{GPa}$ and $11.92 \mathrm{GPa}$, respectively, that is observed for $16 \mathrm{wt} \% \mathrm{ZrO}_{2}$. At the same temperatures, maximum and minimum hardness of 4, 8 and 12 
$\mathrm{wt} \% \mathrm{ZrO}_{2}$ are in between these values. In addition, for all the compositions, hardness increases moderately with $\mathrm{T}_{\mathrm{S}}$. The above increases in the hardness value of the $\mathrm{Al}_{2} \mathrm{O}_{3}-\mathrm{ZrO}_{2}$ composite is related to the density increment. It appears that the phases of the sintered composite have least influence on the hardness.

Elastic modulus of the composite depends on the volume fraction of the phases present and their individual modulus of elasticity. At $1550^{\circ} \mathrm{C}$, densification of the composites is improved by reducing pore volume fraction of the matrix than at $1450^{\circ} \mathrm{C}$ and as a result of which the modulus of elasticity improves. Alumina has a higher modulus of elasticity compared to zirconia. It has been observed that the samples containing $4 \mathrm{wt} \%$ zirconia have the highest modulus of elasticity, whereas specimen containing $16 \mathrm{wt} \%$ zirconia has lower levels of elasticity at a given sintering temperature compared to other samples having lower amount of zirconia. Similar phenomena also have been observed for $1450^{\circ} \mathrm{C}$. For both sintering temperatures, with the increase of zirconia content, the value of elastic modulus decreases, whereas with the increase of temperature, that value of elastic modulus increases. Nicholson [20] established that both Young's modulus and hardness of ZTA composites containing particles of zirconia stabilized with $3 \mathrm{~mol} \%$ yttria followed a linear rule of mixtures.

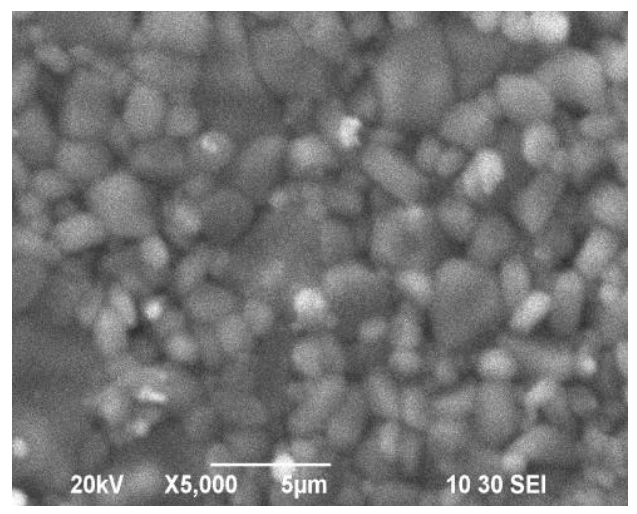

(a) $\mathrm{Al}_{2} \mathrm{O}_{3}$

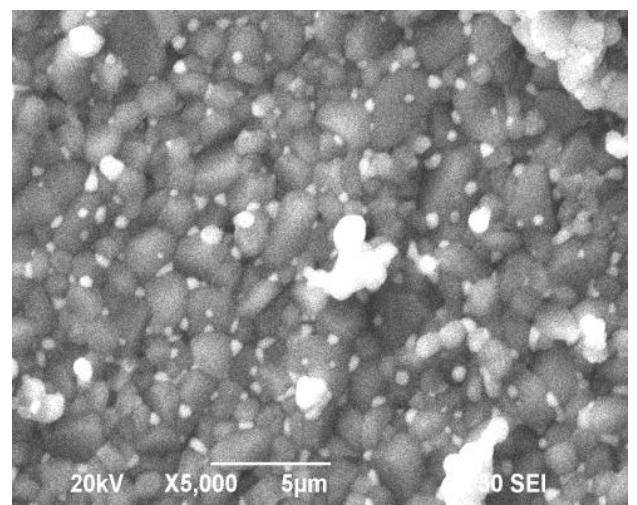

(c) $\mathrm{Al}_{2} \mathrm{O}_{3}+8 \mathrm{wt} \% \mathrm{ZrO}_{2}$

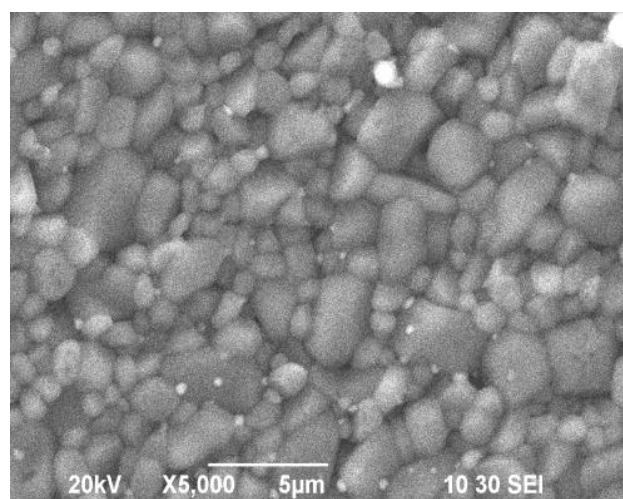

(b) $\mathrm{Al}_{2} \mathrm{O}_{3}+4 \mathrm{wt} \% \mathrm{ZrO}_{2}$

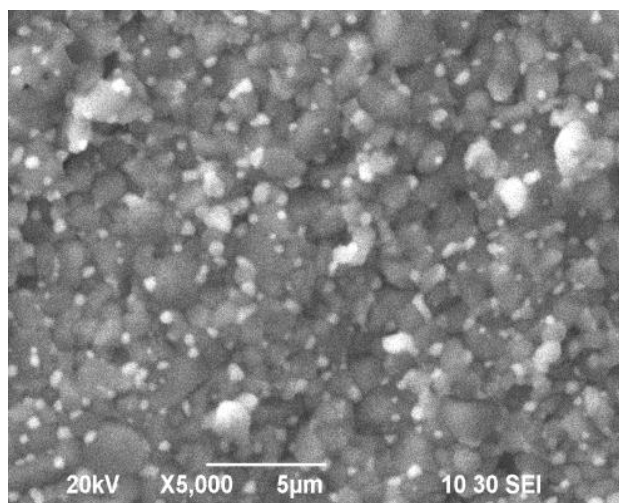

(d) $\mathrm{Al}_{2} \mathrm{O}_{3}+12 \mathrm{wt} \% \mathrm{ZrO}_{2}$

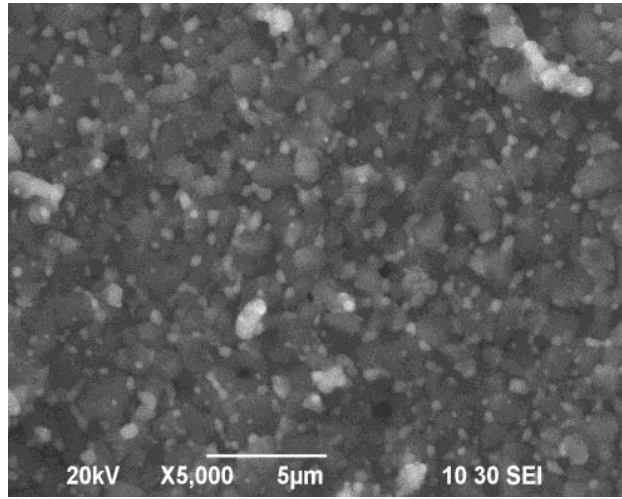

(e) $\mathrm{Al}_{2} \mathrm{O}_{3}+16 \mathrm{wt} \% \mathrm{ZrO}_{2}$

Fig. 5. Microstructure of Different Compositions sintered at $1550^{\circ} \mathrm{C}$ 


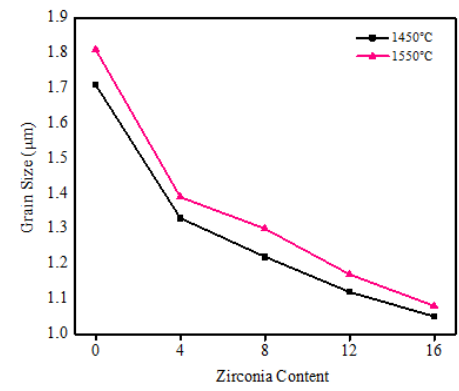
Fig. 6. Variation of grain size with zirconia content at
various sintering temperature.

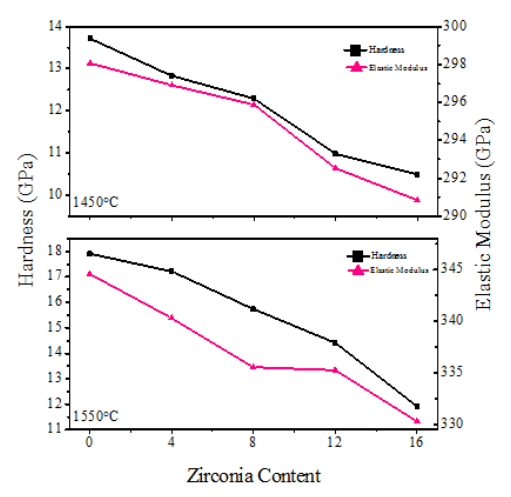

Fig. 7. Variation of hardness and elastic modulus with zirconia content at different sintering temperature.

\subsection{Flexural strength}

The Flexural strength increases linearly with increasing zirconia content as well as sintering temperature that has shown in Fig. 8. The flexural strength was found around $383 \mathrm{MPa}$ for pure $\mathrm{Al}_{2} \mathrm{O}_{3}$ and that of $626 \mathrm{MPa}$ for $16 \mathrm{wt} \%$ of ZTA sintered at $1450^{\circ} \mathrm{C}$ for 2 hours. In addition, about $425 \mathrm{MPa}$ of flexural strength was observed for pure $\mathrm{Al}_{2} \mathrm{O}_{3}$ and $672 \mathrm{MPa}$ for $16 \mathrm{wt} \%$ of $\mathrm{ZTA}$ sintered at $1550^{\circ} \mathrm{C}$. The martensitic transformation and frontal process zone are predominant mechanisms to increase the flexural strength of $\mathrm{Al}_{2} \mathrm{O}_{3^{-}}$ $\mathrm{ZrO}_{2}$ composite. Since the tetragonal zirconia grains do not undergo the stress-induced transformation to the monoclinic form when grain size is smaller than a critical size, then it does not affect the value of flexural strength. Usually, the effect of grain size on strength in transformation-toughened composites is a complex phenomenon [21]. With the increase of sintering temperature, grain growth takes place. An increase in grain size improves the transformability, therefore, increasing strength. The $\mathrm{m}-\mathrm{ZrO}_{2}$ phase increases with increase in $\mathrm{ZrO}_{2}$ content. The retention of $\mathrm{t}-\mathrm{ZrO}_{2}$ varies during fracture and $\mathrm{t}-\mathrm{ZrO}_{2}$ fraction decreases with increasing zirconia content. However, with the increase of sintering temperature, $\mathrm{t}-\mathrm{ZrO}_{2}$ retention becomes much easier to trigger the transformation to monoclinic. As a result, its contribution to transformation toughening predominates although retention of $\mathrm{m}-\mathrm{ZrO}_{2}$ aids to microcrack toughening.

The addition of zirconia is very effective in hindering the grain growth of alumina during sintering, even for the lowest zirconia content. The addition up to $16 \mathrm{wt} \% \mathrm{ZrO}_{2}$ prevents grain growth without allowing the formation of zirconia agglomerates, which are very deleterious for the mechanical stability of the composite. However, the premature zirconia agglomeration can be observed in case of composites containing $15 \mathrm{~mol} \%$ $\mathrm{ZrO}_{2}[19]$.

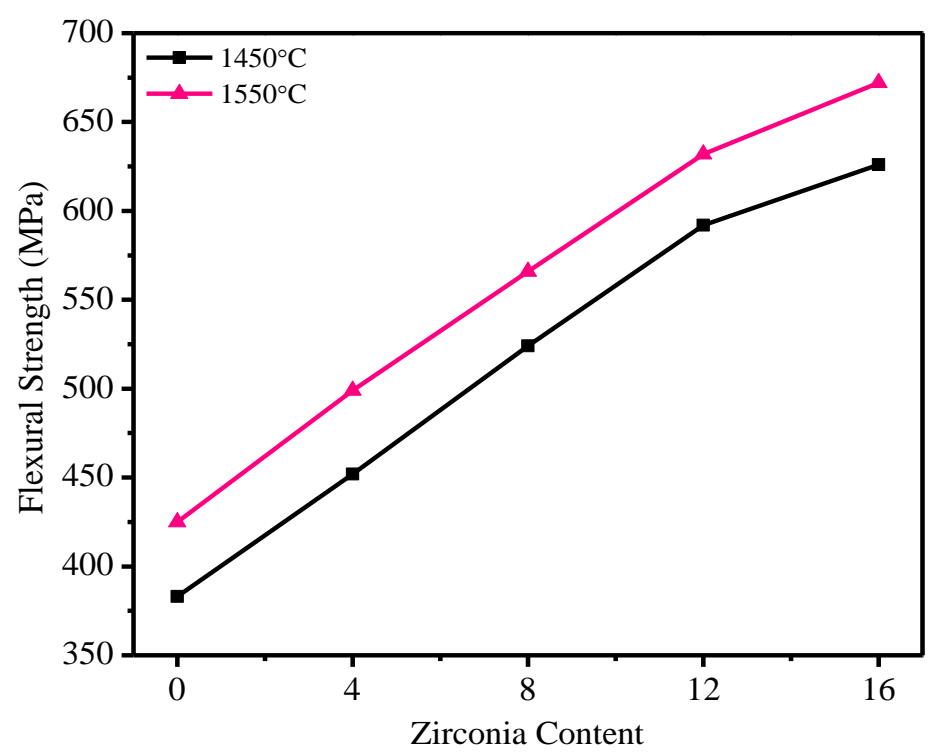

Fig. 8. Variation of Flexural strength with zirconia content at different sintering temperature. 


\section{Conclusion}

The Zirconia-toughened alumina (ZTA) composite has been successfully prepared by slurry method and sintered at $1450^{\circ} \mathrm{C}$ and $1550^{\circ} \mathrm{C}$ for two hours. The change of zirconia content and sintering temperature plays vital role in changing the structural and mechanical properties. The X-ray diffraction studies clearly showed the formation of $\alpha-\mathrm{Al}_{2} \mathrm{O}_{3}, \mathrm{t}$ and $\mathrm{m}-\mathrm{ZrO}_{2}$ phases both in the pure $\mathrm{Al}_{2} \mathrm{O}_{3}$ and in the ZTA composites, respectively. It has been seen that the $\mathrm{ZrO}_{2}$ addition promotes composites with higher densities. The density has been found to increase with increasing zirconia content and sintering temperature, while porosity decreases with the same change of zirconia content and sintering temperature. SEM images show the microstructures of prepared ZTA which reveals that the grains are homogeneous and finer at $1550^{\circ} \mathrm{C}$. It can also be observed that the grain size of $\mathrm{ZrO}_{2}$ decreases with the increase of $\mathrm{ZrO}_{2}$ content, whereas it increases with the increase of sintering temperature and hinders the grain growth of $\mathrm{Al}_{2} \mathrm{O}_{3}$ which contributes to the variation of porosity. Hardness and elastic modulus have been found to be increased with sintering temperature, while the addition of $\mathrm{ZrO}_{2}$ decreases the hardness and elastic modulus of the composite. The flexural strength increases with increasing zirconia content as well as sintering temperature. The martensitic transformation and frontal process zone are predominant mechanisms to increase the flexural strength of $\mathrm{Al}_{2} \mathrm{O}_{3}-\mathrm{ZrO}_{2}$ composite. The zirconia substitution in pure $\mathrm{Al}_{2} \mathrm{O}_{3}$ and the change of sintering temperature was found to have a significant effect on structural and mechanical properties.

\section{Acknowledgment}

The authors are thankful to PP and PDC, BCSIR, Dhaka-1000, Bangladesh for extending experimental facilities.

\section{References}

[1] N. Claussen, J. Am. Ceram. Soc., 59, 1976, 49.

[2] D.W. Shin, K.K. Orr, H. Schubert, J. Am. Ceram. Soc., 73, 1990, 1181.

[3] J. Mullot, J. P. Lecompte, L. Montanaro, A. Negro, J. Euro. Ceram. Soc., 11, 1993, 309.

[4] J. Kishino, A. Nishiyama, T. Sakuma, J. Mater. Sci., 31, 1994, 4991.

[5] R. H. J. Hannink, P. M. Kelly and B. C. Muddle, "Transformation toughening in zirconia-containing ceramics". J. Am. Ceram. Soc., $83,2000,461-487$.

[6] A. H. Heuer and L. W. Hobbs ed., "Advances in Ceramics", Am. Ceram. Soc. Inc., OH, USA, 3, 1981

[7] N. Claussen, M. Ruehle and A. H.Heuer, ed., "Advances in Ceramics", Am. Ceram. Soc, Inc., OH, USA, $12,1984$.

[8] H. Mills and S. Blackburn., et al., "Zirconia toughened aluminas by hydro-thermal processing", J. Eur. Soc., 20, 2000, 1085-1090.

[9] A. Bleier. and C. G. Westmoreland, et al., "Effects of $\mathrm{pH}$ and particle size on the processing of and the development of microstructure in Alumina-Zirconia composites", J. Am. Ceram. Soc., 74, 1991, 3100-11.

[10] T. Suzuki, Y. Sakka, K. Nakano and H. Hiraga, "Effect of ultra-sonication on colloidal dispersions of $\mathrm{Al}_{2} \mathrm{O}_{3}$ and $\mathrm{ZrO}_{2}$ in $\mathrm{pH}$ controlled suspensions", JIM 39, 1998, 682-689.

[11] A. Bleier, P. F. Becher, C. G. Westmoreland and K. B. Alexander, et al., "Effect of aqueous processing conditions on the microstructure and transformation behaviour in $\mathrm{Al}_{2} \mathrm{O}_{3}-\mathrm{ZrO}_{2}\left(\mathrm{CeO}_{2}\right)$ composites, J. Am. Ceram. Soc., 75, 1992, $2649-58$.

[12] R. C. Garvie, et al., "Occurrence of metastable tetragonal zirconia as a crystallite size effect", J. Phys. Chem., 69, 1965, $1238-43$.

[13] N. P. Bansal, S. R. Choi "Processing of Alumina-Toughened $\mathrm{ZrO}_{2}$ Composite", NASA/TM -212451, 2003.

[14] Maria Cecilia, Carlos Nelson EliasI, Jamil Duailibi FilhoII, Leandra Guimarães de OliveiraII, "Mechanical properties of $\mathrm{Al}_{2} \mathrm{O}_{3}$ $\mathrm{ZrO}_{2}$ composites for composite abutments", Mat. Res., Vol. 7, No. 4, 2004, 643-649.

[15] C. Santos, R. C. Souza, J. K. M. F. Daguano, C. N. Elias, S. O. Rogero, “ Development of $\mathrm{ZrO}_{2}-\mathrm{Al}_{2} \mathrm{O}_{3}$ Composite”, The 51st Brazilian Congress on Composites, 2007.

[16] Willi Pabst, Eva Gregorova, Gabriela Ticha, Eva Tynova, "Effective Elastic Properties of $\mathrm{Al}_{2} \mathrm{O}_{3}-\mathrm{ZrO}_{2}$ Composite Composites Part 4. Tensile Modulus of Porous $\mathrm{Al}_{2} \mathrm{O}_{3}$ and $\mathrm{ZrO}_{2}$ ", Composites - Silikáty Vol. 48, No. 4, 2004, 165-174.

[17] A. Bleier, P. F. Becher, C. G. Westmoreland and K. B. Alexander, "Effect of aqueous processing conditions on the microstructure and transformation behavior in $\mathrm{Al}_{2} \mathrm{O}_{3}-\mathrm{ZrO}_{2}\left(\mathrm{CeO}_{2}\right)$ composites", J. Am. Ceram. Soc., Vol. 75, pp 1992, 2649-58.

[18] R. P. Rana, "Powder processing, densification behaviour, microstructure and mechanical properties of $\mathrm{Al}_{2} \mathrm{O}_{3}-50$ vol\% $\mathrm{ZrO}_{2}$ composites", Ph. D. Thesis, National Institute of Technology Rourkela, 2009.

[19] B. Basu, T. Venkateswaran, D. Sarkar, "Pressureless sintering and tribological properties of WC-ZrO $\mathrm{W}_{2}$ composites", J. Eur. Ceram. Soc., 25 (9), 2005, 1603-10.

[20] A. K. Khaund, P. S. Nicholson, "Fracture of a brittle composite: Influence of elastic mismatch and interfacial bonding", J. Mater. Sci., 15, 1980, 177.

[21] G. Orange, G. Fantozzi, P. Homerin, F. Thevenot, A. Leriche, "Thermomechanical Properties of Zirconia-Toughened Alumina Materials: Effect of Microstructure and Temperature on Toughening Mechanisms", Advances in Composites, Vol24B, Science and Technology of Zirconia III, Edited by A. Somiya, N. Yamamoto, H. Yanagida, The American Composite Society, Inc. O. H. Westerville, (1988), 1075-82. 